\title{
A EDUCAÇÃO POPULAR LATINO-AMERICANA E SUAS CONTRIBUIÇÕES PARA A MUDANÇA SOCIAL
}

\author{
LATIN AMERICAN POPULAR EDUCATION \\ AND ITS CONTRIBUTIONS TO \\ SOCIAL CHANGE
}

\section{LA EDUCACIÓN POPULAR LATINOAMERICANA \\ Y SUS CONTRIBUCIONES \\ AL CAMBIO SOCIAL}

\author{
João Colares da Mota Neto ${ }^{1}$
}

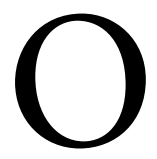

bservamos, no Brasil e em outros países da América Latina e do mundo, uma ofensiva conservadora no campo ideológico, que não apenas tenta desqualificar o pensamento crítico - não raro com argumentos frágeis, sem qualquer sustentação científica ou filosófica mais sólida -, como também, e o que é mais grave, busca interditar o debate de ideias, a autonomia de pensamento e a liberdade de cátedra.

$\mathrm{Na}$ área da educação, projetos como o "Escola Sem Partido" e o de militarização das escolas públicas, a extinção da Secretaria de Educação Continuada, Alfabetização, Diversidade e Inclusão (SECADI) da estrutura do Ministério da Educação e a perseguição ideológica ao pensamento de Paulo Freire são exemplos de políticas levadas a cabo pelo governo de Jair Bolsonaro, as quais põem em risco o direito à educação pública e ameaçam o livre pensar.

Ao analisar o projeto "Escola Sem Partido", Gaudêncio Frigotto aponta suas relações com a tentativa de destruição da educação pública como direito social e subjetivo. Trata-se de um processo guiado por interesses mercadológicos, que "abriu o caminho para a gestão privada ou com critérios privados da escola pública", a qual busca "se apropriar por dentro, com a anuência de grande parte dos governantes, da definição do conteúdo, do método e da forma da escola pública” (FRIGOTTO, 2016, p. 11).

Políticas educacionais de viés autoritário, conservador e a serviço do mercado têm sido aprofundadas nos últimos anos no Brasil, particularmente nos governos de Michel Temer e de Jair Bolsonaro. Todavia, essas políticas, vale dizer, conforme Luiz Fernandes Dourado, não se limitam a nosso país e estão conectadas a um movimento global de busca pela expansão do capital, por meio de reformas neoliberais, "sob o eixo da redução do Estado nas políticas sociais e sua retomada para a expansão do capital” (2019, p. 3).

Nesse cenário conflituoso e de disputas ideológicas em torno de projetos de sociedade e educação, é de suma importância a publicação do livro A Educação Popular Latino-Americana: História e Fundamentos Éticos, Políticos e Pedagógicos, de Oscar Jara, editado em conjunto pela Ação Educativa, pelo Conselho de Educação Popular da América Latina e do Caribe (CEAAL) e pela Escola Nacional de

Resenha do Livro: A educação popular latino-americana: História e fundamentos éticos, políticos e pedagógicos de Oscar Jara. São Paulo: Ação Educativa/CEAAL/ENFOC, 2020.

1.Universidade do Estado do Pará- Programa de Pós-Graduação em Educação - Belém (PA), Brasil. E-mail: joaocolares@hotmail.com 
Formação da Confederação Nacional dos Trabalhadores na Agricultura (CONTAG), a ENFOC. Trata-se de uma tradução para o português de La Educación Popular Latinoamericana: Historia y Claves Éticas, Políticas y Pedagógicas, publicado pelo autor na Costa Rica, em 2018, por CEP Alforja, CEAAL, Intered e Alboan, tendo como texto-base sua tese de doutorado em educação, defendida na Universidad da Costa Rica, em 2017.

Nesse livro, Jara (2020) analisa e interpreta os fundamentos éticos, políticos e pedagógicos da educação popular na América Latina, entendida como "fenômeno sociocultural", "concepção educativa" e "movimento de educadoras e educadores". O autor também relaciona esses fundamentos aos processos e propostas de mudança social levados a cabo por movimentos sociais e populares, bem como por governos progressistas ao longos das últimas seis décadas no continente latino-americano. É apresentado um panorama histórico da educação popular, estruturada em cinco períodos, marcados por eventos significativos de processos de mudança social na América Latina: 1) da Revolução Cubana ao Governo da Unidade Popular no Chile (1959-1970); 2) do Governo da Unidade Popular no Chile ao triunfo da Insurreição Popular Sandinista (1970-1979); 3) do triunfo da Insurreição Popular Sandinista ao levante indígena zapatista (1979-1994); 4) do levante indígena zapatista ao I Fórum Social Mundial (1994-2001); 5) do I ao XIII Fórum Social Mundial (2001-2018).

Trata-se de um estudo rigoroso, produzido não apenas por um dos maiores especialistas em educação popular do continente, mas também por um profundo conhecedor da história da educação popular; alguém que participou ativamente dos Movimentos de Educação Popular em vários países da América Latina e que continua contribuindo nessa direção nos últimos anos, como Presidente do CEAAL - entidade da qual faz parte desde sua fundação, em 1982, juntamente com Paulo Freire, Carlos Rodrigues Brandão e outros(as) educadores(as).

A vinculação da editoração do livro com o CEAAL guarda relação, também, com a Campanha Latino-Americana e Caribenha em Defesa do Legado de Paulo Freire, impulsionada pelo CEAAL, por centenas de movimentos sociais, entidades da sociedade civil, universidades, sindicatos, associações científicas e milhares de professores(as), educadores(as) populares, artistas e personalidades políticas de todo o mundo. O livro foi traduzido para o português, nesse sentido, não apenas como forma de dar acesso, para o público brasileiro, à mais recente obra de Oscar Jara, mas também porque, por meio da leitura do livro, pode-se aprofundar a compreensão dos fundamentos da educação popular e destacar a enorme contribuição de Paulo Freire para a história do pensamento pedagógico latino-americano e mundial.

O livro está organizado em cinco capítulos, antecedidos por um prefácio à edição brasileira escrito por Pedro de Carvalho Pontual e um prefácio à edição em língua espanhola por Carlos Rodrigues Brandão. No prefácio de Brandão, ele afirma sobre Oscar Jara:

"Faço lembrar que, mais que um estudioso acadêmico, ele é um educador popular de extensas trilhas, largos e esperançosos horizontes. E é, provavelmente, o mais confiável especialista na arte de sistematizar experiências de vocação popular e emancipatórias" (2020, p. 14).

Do prefácio de Pedro de Carvalho Pontual, destaco a menção de que o livro de Oscar Jara reconhece o notável legado de Paulo Freire na trajetória da educação popular na América Latina, movimento que teve a participação de muitos atores sociais e "a contribuição de teorizadores de suas práticas em variados países, dentre os quais Oscar Jara se constitui como um dos mais importantes protagonistas, sobretudo por sua contribuição ao processo de sistematização de experiências" (2020, p. 7-8). 
No primeiro capítulo do livro, Oscar Jara conceitua e caracteriza a educação popular. No segundo, discute as relações entre educação e mudança social, identificando vínculos, dilemas e desafios éticos, políticos e pedagógicos. O terceiro capítulo está dedicado a apresentar escolhas e perspectivas metodológicas do estudo, buscando, na própria educação popular, os fundamentos para a produção do conhecimento. No quarto capítulo, o autor apresenta o panorama histórico da educação popular na América Latina, considerando o que chama de antecedentes (século XIX e primeira metade do século XX) e os cinco períodos históricos já citados, cobrindo seis décadas, que vão da Revolução Cubana (1959) ao XIII Fórum Social Mundial, na Bahia (2018). No quinto capítulo, o autor analisa as contribuições da educação popular, ancorada em seus fundamentos éticos, políticos e pedagógicos, para a mudança social.

O livro finaliza com um epílogo, que sistematiza as principais considerações do autor sobre o tema do estudo, e com uma interessante cronologia de eventos e publicações regulares sobre a educação popular na América Latina no período de 1970 a 2018.

Dentre as conclusões do livro, destaca-se a afirmação de que os processos de educação popular na América Latina "têm um acumulado e um fundamento teórico e prático consistente e original que constituem a Educação Popular como uma corrente pedagógica crítica com capacidade de proposição para a educação em geral e em particular para as relações entre educação e mudança social” (JARA, 2020, p. 223). O autor também sustenta que a educação popular produz aportes significativos para repensar a educação diante dos desafios contemporâneos, nos seguintes aspectos: a) pensar em outro sistema educativo, com outras características e outras lógicas; b) contribuir para a democratização das políticas públicas, devendo assumir um caráter mais participativo; c) gerar inovações educativas e replanejar a formação docente; d) associar a concepção de educação de pessoas jovens e adultas ao direito à educação e ao aprendizado ao longo da vida; e) considerar os debates e as propostas atuais sobre a qualidade da educação.

Em suma, para o autor, a educação popular latino-americana realiza e esboça propostas sobre um tipo de educação que permita às pessoas se construir como sujeitos com capacidades de transformação pessoal e social. Isso pressupõe, na análise de Jara (2020), romper com a ordem social imperante marcada pela globalização neoliberal; questionar os estereótipos e padrões ideológicos e éticos dominantes de nossas sociedades capitalistas, racistas, colonialistas e patriarcais; ter a capacidade de aprender e desaprender permanentemente, de pensar e atuar de forma crítica, autônoma e criativa; e imaginar e criar novos espaços e relações democráticas entre os seres humanos nos diversos âmbitos da vida social, suscitando, ainda, uma consciência ecológica que transforme as relações do ser humano com o meio ambiente.

Trata-se de um livro, portanto, extremamente importante na conjuntura atual, que nos desafia a pensar criativamente em modos de sociabilidade "outros", em pedagogias "outras", que enfrentem as perspectivas hegemônicas neoliberais e possam se relacionar, por exemplo, à imaginação social radical das classes populares e dos movimentos sociais da América Latina, bem como às cosmovisões e sabedorias insurgentes dos povos originários de Abya Yala, com os quais temos muito a aprender para continuar, enriquecer e reinventar a história da educação popular.

\section{Referências}

BRANDÃO, C. R. Prefácio à edição em língua espanhola. In: JARA, O. A educação popular latinoamericana: História e fundamentos éticos, políticos e pedagógicos. São Paulo: Ação Educativa/CEAAL/ ENFOC, 2020. 
DOURADO, L. F. Estado, educação e democracia no Brasil: Retrocessos e resistências. Educação \& Sociedade, Campinas, v. 40, p. 1-24, 2019. https://doi.org/10.1590/es0101-73302019224639

FRIGOTTO, G. "Escola Sem Partido": Imposição da mordaça aos educadores. e-Mosaicos, Rio de Janeiro, v. 5, n. 9, p. 11-13, jun. 2016. https://doi.org/10.12957/e-mosaicos.2016.24722

JARA, O. A educação popular latino-americana: História e fundamentos éticos, políticos e pedagógicos. São Paulo: Ação Educativa/CEAAL/ENFOC, 2020.

PONTUAL, P. C. Prefácio à edição brasileira. In: JARA, O. A educação popular latino-americana: História e fundamentos éticos, políticos e pedagógicos. São Paulo: Ação Educativa/CEAAL/ENFOC, 2020 .

\section{Sobre o Autor}

João Colares da Mota Neto é doutor em Educação pela Universidade Federal do Pará (UFPA), com doutorado sanduíche na Universidad Pedagógica Nacional de Colombia. Professor do Programa de Pósgraduação em Educação e da Licenciatura em Pedagogia da Universidade do Estado do Pará (Uepa). Coordenador da Rede de Pesquisa sobre Pedagogias Decoloniais na Amazônia.

Recebido: 04 abr. 2020

Aceito: 27 abr. 2020 